\title{
Escala sobre o Clima para Criatividade em Sala de Aula ${ }^{1}$
}

\author{
Denise de Souza Fleith ${ }^{2}$ \\ Universidade de Brasília \\ Eunice M. L. Soriano de Alencar \\ Universidade Católica de Brasília
}

\begin{abstract}
RESUMO - O propósito deste estudo foi construir e validar uma escala sobre o clima para criatividade em sala de aula. Este instrumento visa auxiliar na identificação de fatores que contribuem para a expressão da criatividade em sala de aula, bem como aqueles que inibem a criatividade em turmas de $3^{\text {a e }} 4^{\text {a }}$ séries do ensino fundamental. A escala intitulada "Minha Sala de Aula" foi aplicada em 644 alunos de escolas públicas e particulares. Para exame da validade de construto do instrumento, utilizou-se uma análise fatorial exploratória. A análise gerou cinco fatores: Suporte da Professora à Expressão de Idéias do Aluno, Autopercepção do Aluno com Relação à Criatividade, Interesse do Aluno pela Aprendizagem, Autonomia do Aluno e Estímulo da Professora à Produção de Idéias do Aluno. Os coeficientes de fidedignidade variaram de 0,55 a 0,73.
\end{abstract}

Palavras-chave: criatividade; clima em sala de aula; ensino fundamental.

\section{Scale of the Classroom Climate for Creativity}

\begin{abstract}
The purpose of this study was to design and validate a scale on the classroom climate for creativity. This instrument aims to help in the identification of factors that contribute to the expression of creativity in the classroom, as well as those that inhibit the development of creativity in $3^{\text {rd }}$ and $4^{\text {th }}$ grade elementary school. The scale entitled "My Classroom" was administered to 644 elementary school students from public and private schools. An exploratory factor analysis was carried out to get evidence on the construct validity. This analysis generated five factors: Teacher's Support to Student's Ideas Expression, Student's Self-Perception on Creativity, Student's Interest for Learning, Student's Autonomy and Teacher's Incentive to Student's Ideas Production. The reliability coefficients varied from .55 to .73 .
\end{abstract}

Key words: creativity; climate in the classroom; elementary school level.

$\mathrm{O}$ interesse em criatividade como uma área de pesquisa educacional floresceu na segunda metade do século XX. Desde então, os resultados da pesquisa em criatividade têm influenciado práticas educacionais, objetivos de ensino, estratégias de ensino e até o ambiente físico da escola (Torrance, 1983). Educadores e psicólogos têm enfatizado a importância de se promover condições favoráveis ao desenvolvimento do potencial criativo dos alunos. Como conseqüência, muitos estudos (Alencar, 1990; Alencar \& Fleith, 2003; Amabile, 1989; Cropley, 1997; Daniels, 1997; Piirto, 1992; Starko, 1995; Sternberg \& Williams, 1996) têm sugerido formas de se cultivar a criatividade no contexto educacional. Alguns esforços têm também sido feitos no sentido de se discutir os fatores que constituem barreiras ao comportamento criativo em sala de aula (Alencar \& Fleith, 2004a; Alencar, Fleith \& Virgolim, 1995; Sterling, 2003).

Apesar do reconhecimento de que o ambiente educacional tem um papel importante no desenvolvimento da expressão criativa dos alunos, poucas tentativas têm sido feitas para se avaliar a extensão em que a criatividade tem sido estimulada ou inibida neste contexto. Neste sentido, a proposta deste estudo foi a de desenvolver um instrumento que avaliasse o clima de sala de aula com relação à criatividade dos estudantes.

1 Trabalho desenvolvido com auxílio do CNPq.

2 Endereço: Universidade de Brasília, Instituto de Psicologia, Brasília, DF, Brasil 70910-900. E-mail: fleith@unb.br

\section{O Papel do Ambiente no Desenvolvimento e Expressão da Criatividade}

Os pesquisadores da área vêm propondo distintas conceituações para o termo criatividade, paralelamente a uma análise dos processos envolvidos no ato criativo. Entretanto, não existe uma definição consensual de criatividade, observando-se que as várias definições de criatividade podem ser distribuídas em quatro categorias: pessoa, produto, processo e ambiente. Segundo Tardiff e Sternberg (1988), as definições que focalizam a pessoa incluem três aspectos: características cognitivas, traços de personalidade e experiências durante o desenvolvimento (por exemplo, ser o primeiro filho, ter muitos hobbies). A segunda categoria de definições de criatividade enfatiza as características do produto final. Ele deve ser novo, útil e de valor para a sociedade. A terceira categoria diz respeito ao processo ou como desenvolver produtos criativos. $\mathrm{O}$ processo criativo pode envolver uma maneira original para produção de idéias incomuns, combinações diferentes ou transformação de uma idéia já existente. Finalmente, as definições agrupadas na quarta categoria enfatizam o papel do ambiente na promoção ou inibição de habilidades criativas. Esta última perspectiva questiona a visão de criatividade como um processo que considera apenas o indivíduo (Amabile, 1996; Csikszentmihalyi, 1996). Nesta perspectiva, criatividade é o resultado de um grande sistema de redes sociais, domínios de cultura e campos (ou instituições sociais). O indivíduo é apenas uma parte deste 
processo interativo. Amabile (2001) chama a atenção para a importância de um ambiente social que favoreça o desenvolvimento de motivações, atitudes e habilidades e que crie oportunidades de aprendizagem criativa e envolvimento com tarefas desafiadoras.

Neste sentido, Csikszentmihalyi (1988, 1999) sugere que a questão mais importante em criatividade é "onde está a criatividade" e não "o que é criatividade". Ele acredita que criatividade resulta da interação de um sistema composto de três subsistemas: pessoa, domínio e campo.

Cada subsistema interage com os outros: indivíduos adquirem conhecimento de domínios desafiadores, propõem um novo conhecimento para estes domínios e têm o novo conhecimento avaliado pelo campo. Caso o novo conhecimento seja aceito pelo campo, ele se torna parte dele e é acrescentado ao domínio. (Feldman, Csikszentmihalyi \& Gardner, 1994, p. 20)

Domínio é definido como um corpo organizado de conhecimento associado a um dado campo. Campo, por sua vez, inclui todas as pessoas que podem afetar a estrutura do domínio. "Ele consiste de professores, juízes, instituições, agências, prêmios ... que permitem ou minam o desenvolvimento de uma carreira e a produção de trabalhos criativos" (Gardner \& Wolf, 1994, p. 57). Finalmente, o subsistema pessoa engloba a bagagem genética e experiências pessoais.

$\mathrm{O}$ ambiente pode afetar a produção de algo novo, bem como sua aceitação. $\mathrm{O}$ estudo do indivíduo não é suficiente para explicar o fenômeno da criatividade. De acordo com Csikszentmihalyi (1996): "É mais fácil estimular a criatividade mudando as condições do ambiente do que tentando fazer as pessoas pensarem mais criativamente" (p.1).

Segundo Csikszentmihalyi (1999), para se aumentar a freqüência da produção de novas idéias que sejam de valor para a cultura, é necessário focalizar na pessoa e nas contribuições do campo e do domínio. No que diz respeito à pessoa, interesses e curiosidade podem ser estimulados através de experiências positivas e de um ambiente encorajador da expressão criativa. Da mesma forma, exposição precoce e oportunidade de se engajar em um domínio específico são fatores essenciais ao desenvolvimento do potencial criativo do indivíduo. Identificar os interesses do aluno e encorajar o seu envolvimento em alguma área do conhecimento são condições favoráveis ao desenvolvimento da criatividade.

Com respeito à influência do campo na criatividade, há quatro aspectos que contribuem de forma significativa para a produção criativa: treinamento, recursos, reconhecimento e recompensa. Uma sociedade que efetivamente promove oportunidades de desenvolvimento de habilidades estará contribuindo para o desenvolvimento de talentos criativos. Recursos são também indispensáveis para que a criatividade floresça. É importante ainda que o potencial e interesse dos jovens sejam reconhecidos por um membro mais experiente do campo. Neste sentido, o papel do mentor é o de encorajar o jovem a continuar trabalhando em uma área do conhecimento ou domínio. O jovem aluno deve ter ainda motivação de empregar suas habilidades em uma carreira produtiva. Finalmente, recompensas intrínsecas e extrínsecas podem contribuir para o desenvolvimento da criatividade.
A contribuição da dimensão domínio para a estimulação da criatividade se manifesta na medida em que o conhecimento é organizado e a informação é de fácil acesso. "Sempre que a informação é falsa, ilógica, superficial, redundante, desconexa, confusa ou, especialmente, sem importância, as chances de ser assimilada pelos alunos são pequenas, e é também remota a probabilidade de uma resposta criativa" (Csikszentmihalyi, 1996, p. 341). Criatividade, também, é cultivada quando o indivíduo tem acesso a muitas fontes de informação.

Amabile (1989) considera a criatividade como resultado da interação de três componentes: habilidades do domínio, habilidades de pensamento criativo e técnicas e motivação intrínseca. Habilidades do domínio incluem educação, conhecimento, habilidades técnicas e experiência em uma área específica. Habilidades de pensamento criativo e de trabalho "são estilos de trabalho, estilos de pensamento e traços de personalidade que possibilitam as pessoas usarem suas habilidades de domínio de novas maneiras" (p. 46). Motivação intrínseca diz respeito ao desejo de se envolver em uma tarefa porque é interessante, desafiadora e prazerosa. Embora os componentes desse modelo sejam de natureza intrapessoal, o ambiente tem um papel importante no desenvolvimento da criatividade. Ele tem influência em cada componente e no processo total.

Estudos conduzidos por Alencar (1997) e Alencar, Collares, Dias e Julião (1993) indicaram que tanto no contexto universitário como no ensino médio, de acordo com a percepção dos alunos, a criatividade é pouco incentivada pelos professores. Os programas das disciplinas tampouco favorecem o desenvolvimento e expressão da criatividade do aluno. Também Alencar, Fleith e Martinez (2003) examinaram obstáculos à criatividade pessoal entre estudantes universitários brasileiros e mexicanos. Os resultados indicaram que falta de tempo e oportunidade foi a barreira mais freqüentemente mencionada pelos estudantes. Diferenças significativas foram observadas entre estudantes brasileiros e mexicanos em relação aos obstáculos associados à falta de motivação. $\mathrm{O}$ escore obtido pelos mexicanos foi superior ao dos brasileiros, sugerindo que a falta de motivação é um obstáculo mais presente na realidade mexicana em comparação com a brasileira. Foram, ainda, observadas diferenças entre estudantes do gênero masculino e feminino em relação à inibição e timidez, sendo que as mulheres apresentaram um escore maior do que os homens. Dando continuidade a esta linha de pesquisa, Alencar e Fleith (2004b) construíram e validaram um instrumento para investigar a percepção de estudantes universitários quanto ao grau de incentivo à criatividade por parte de seus professores.

Resultados semelhantes foram obtidos por Fleith (2000), ao investigar os fatores que estimulam e inibem a criatividade em salas de aula do ensino fundamental. Professores e alunos de $3^{\mathrm{a}}$ e $4^{\mathrm{a}}$ séries sugeriram que um ambiente estimulador da criatividade oferece escolhas aos alunos, caracterizando-se pela aceitação de idéias diferentes, encorajamento da autoconfiança e foco nos interesses e habilidades dos alunos. Por outro lado, os participantes do estudo indicaram que, em um ambiente inibidor da criatividade, as idéias são ignoradas, os professores são controladores, erros não são permitidos e regras existem em excesso. 
Portanto, a criação de um ambiente harmonioso, estimulador e significativo pode contribuir para o desenvolvimento do potencial criativo. No contexto educacional, um ambiente que estimula a criatividade inclui os seguintes fatores (Sternberg, 2003): (a) alocar tempo para o pensamento criativo, (b) recompensar idéias e produtos criativos, (c) encorajar o aluno a correr riscos, (d) aceitar o erro como parte do processo de aprendizagem, (e) possibilitar aos alunos imaginar outros pontos de vista, (f) propiciar oportunidades para a exploração do ambiente e questionamento de pressupostos, (g) identificar interesses, (h) formular problemas, (i) gerar múltiplas hipóteses e (j) focalizar em idéias gerais ao invés de fatos específicos.

Amabile $(1989,1996)$ também sugere alternativas de como manter a criatividade viva na escola: (a) fornecer feedback construtivo e significativo, (b) envolver os alunos na avaliação do próprio trabalho e na aprendizagem através dos próprios erros, (c) dar aos alunos possibilidade de escolha, (d) enfatizar cooperação ao invés de competição, (e) prover a sala de aula com material diversificado e abundante, (f) prover oportunidades de experiências de aprendizagem próximas às da vida real, (g) encorajar os alunos a compartilhar seus interesses, experiências, idéias e materiais em sala de aula e (h) prover um ambiente de aprendizagem que seja percebido como importante e divertido.

Alencar (1990) e Fleith (2002) ressaltam ainda como características de um clima criativo em sala de aula: (a) proteger o trabalho criativo do aluno da crítica destrutiva, (b) desenvolver nos alunos a habilidade de pensar em termos de possibilidade, de explorar conseqüências, de sugerir modificações e aperfeiçoamentos para as próprias idéias, (c) encorajar os alunos a refletir sobre o que eles gostariam de conhecer melhor, (d) não se deixar vencer pelas limitações do contexto em que se encontra, mas fazer uso dos próprios recursos criativos para contornar obstáculos, (e) envolver o aluno na solução de problemas do mundo real, (f) possibilitar ao aluno participar na escolha dos problemas a serem investigados, e $(\mathrm{g})$ encorajar o aluno a elaborar produtos originais.

Os estudos em criatividade sugerem que, para se obter uma visão abrangente do desenvolvimento da criatividade no contexto educacional, é essencial considerar o clima de sala de aula. Como expressa Sternberg e Lubart (1999), " $O$ indivíduo precisa de um ambiente que encoraje e reconheça suas idéias criativas. O indivíduo pode ter todas as condições internas necessárias ao desenvolvimento do pensamento criativo, mas sem o estímulo do ambiente, sua criatividade nunca se manifestarâ" (p. 11).

Apesar da importância atribuída ao papel do clima de sala de aula no desenvolvimento da criatividade, constata-se a inexistência, em nosso país, de instrumentos para avaliar a extensão em que este componente tem estimulado ou inibido o comportamento criativo de alunos, especialmente nos anos iniciais de escolarização. Mesmo em países onde a criatividade vem sendo objeto de maior número de investigações, observa-se uma carência de estudos voltados para o desenvolvimento de instrumentos para avaliar o clima de sala de aula (Soh, 2000; Treffinger, 2003). Estudos sobre o clima para a criatividade têm sido mais comuns no contexto das organizações, havendo vários instrumentos construídos para este fim. Nos Estados Unidos, o mais conhecido é de autoria de Amabile e Gryskiewicz (1989). Recentemente, Isaksen, Lauer, Ekvall e Britz (2001) apresentaram uma versão preliminar do Questionário de Visão Situacional, que tem como objetivo avaliar em que extensão o clima organizacional está estimulando ou inibindo as habilidades criativas dos indivíduos. No Brasil, Bruno-Faria e Alencar (1998) construíram e validaram também um conjunto de escalas denominado Indicadores de Clima para a Criatividade, com este mesmo objetivo: identificar estímulos e barreiras à criatividade no ambiente de trabalho.

A relevância do tema e a carência de instrumentos na área levaram-nos ao desenvolvimento do presente estudo, que teve como objetivo construir e validar uma escala sobre o clima de sala de aula para a criatividade, que pudesse ser utilizada para fins de diagnóstico, a partir da identificação de fatores estimuladores e inibidores à expressão do talento criativo nas $3^{\mathrm{a}}$ e $4^{\mathrm{a}}$ séries do ensino fundamental. Com base na identificação destes fatores, estratégias de intervenção poderão ser planejadas no sentido de se promover o estabelecimento de condições favoráveis ao desenvolvimento e expressão do potencial criativo em sala de aula. Este instrumento poderá ainda ser utilizado na coleta de dados de pesquisas futuras na área de criatividade. É indiscutível que neste milênio que ora se inicia, torna-se imprescindível a promoção de talentos criativos produtores de novas idéias e soluções, a fim de que os problemas e desafios enfrentados pela sociedade sejam respondidos de forma eficaz (Virgolim, 1994). Nota-se que este é um momento da História em que a importância e demanda por criatividade vêm sendo amplamente reconhecidas até mesmo por políticos, como Tony Blair, primeiro ministro da Inglaterra, que profetizou que no atual século presenciaríamos uma economia global dominada pela utilização das mentes criativas (Fletcher, 1997). Os sistemas educacionais estão, entretanto, mal equipados para assegurar o florescimento da criatividade.

\section{Método}

\section{Participantes}

Participaram do estudo 644 alunos de $3^{\mathrm{a}}$ e $4^{\mathrm{a}}$ séries do ensino fundamental, sendo $346(53,7 \%)$ do gênero masculino e $297(46,1 \%)$ do feminino. Um aluno não respondeu à questão. Trezentos e oitenta e dois $(59,3 \%)$ alunos cursavam a $3^{\text {a }}$ série e $260(40,4 \%)$ a $4^{\mathrm{a}}$ série. Dois alunos não indicaram a série em que estavam matriculados. Dentre os 644 participantes, $215(33,4 \%)$ freqüentavam escolas públicas e $428(66,5 \%)$ escolas particulares. Um aluno não informou o tipo de escola que freqüentava. A idade média dos participantes era de 9,36 anos, variando de 7 a 13 anos.

\section{Procedimentos}

Bolsistas de Iniciação Científica e alunos de graduação do curso de Psicologia matriculados em pesquisa foram treinados para aplicação do instrumento. Inicialmente estes alunos, portando uma carta de apresentação redigida pelas coordenadoras do projeto, estabeleceram contatos com diretores, coordenadores e/ou professores de distintas escolas no sentido de solicitar 
colaboração no projeto. No caso das escolas públicas, foi solicitada, pelas coordenadoras do projeto, uma autorização por parte da Diretoria de Ensino Fundamental da Secretaria de Educação do Distrito Federal para realização do estudo. A autorização foi concedida. A aplicação dos instrumentos foi realizada por duplas de auxiliares de pesquisa em horário previamente agendado pela coordenadora ou professora da turma. A aplicação, com duração de cerca de 15 minutos, foi coletiva e, na maioria das vezes, a professora se retirou da sala de aula. Foi assegurado aos participantes do estudo o caráter confidencial de suas respostas.

\section{Etapas da construção do instrumento}

Cinqüenta e um itens compuseram a primeira versão do instrumento Escala sobre o Clima para Criatividade em Sala de Aula, desenvolvidos com base na revisão de literatura. Todos os itens do instrumento foram escritos de forma afirmativa de maneira a evitar problemas de compreensão por parte dos alunos que responderão ao instrumento, conforme sugere Gable e Wolf (1993). Para que os itens fossem respondidos, utilizou-se uma escala de freqüência de cinco pontos: (1) nunca, (2) raramente, (3) algumas vezes, (4) muitas vezes e (5) sempre. Todos os cinco pontos da escala foram indicados por escrito e representados graficamente, gradualmente, por faces do tipo triste e feliz (ex: $:(-)$ ).

Em seguida, foi solicitado a professores de $3^{\mathrm{a}}$ e $4^{\mathrm{a}}$ séries que analisassem os itens da escala com vistas a verificar se a linguagem utilizada era clara e adequada aos alunos deste nível de escolarização. Treze itens foram mantidos, 13 foram reescritos e 25 foram retirados. A segunda versão da escala foi constituída, portanto, de 26 itens. Houve, também, uma mudança com relação à escala de frequiência: o termo "raramente" que designa o ponto (2) passou a ser denominado "poucas vezes". Outra mudança foi com relação à representação gráfica da escala. Optou-se por utilizar apenas faces felizes, porém de tamanhos que aumentavam gradualmente

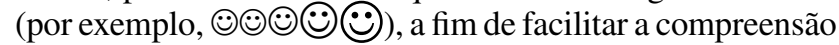
dos jovens alunos que responderão ao instrumento.

Posteriormente, realizou-se um estudo piloto com o objetivo de avaliar semanticamente os itens construídos, a fim de se garantir a sua compreensão, evitando ambigüidade e formulações pouco apropriadas. Para tal, o instrumento foi aplicado, pelos auxiliares de pesquisa, em 80 alunos de $3^{\mathrm{a}}$ série e 50 alunos de $4^{\mathrm{a}}$ série de duas escolas públicas e duas escolas particulares do Distrito Federal. Os auxiliares explicaram aos alunos os objetivos do estudo, forneceram instruções de preenchimento do instrumento e lerem em voz alta os itens do mesmo. Em todas as etapas foi perguntado aos alunos se havia alguma dúvida em relação aos procedimentos para responder ao instrumento, à compreensão dos itens e do significado das palavras contidas na escala.

Em seguida, procedeu-se à reformulação de nove itens com vistas a adequar a linguagem do instrumento ao público-alvo. Um item, relativo ao uso de computador, foi descartado, pois nem todas as escolas dispõem desta máquina. Deste procedimento, resultaram 25 itens que compuseram o instrumento, o qual foi, então, aplicado em uma amostra de 644 alunos de $3^{\mathrm{a}}$ e $4^{\mathrm{a}}$ séries do ensino fundamental, visando obter dados para validação do mesmo.

\section{Análise dos dados}

Para estabelecer a validade de construto do instrumento foi verificada sua estrutura interna por meio de análise fatorial. Utilizando-se o pacote estatístico SPSS 8.0 (1998), realizou-se uma análise fatorial dos eixos principais, com rotação varimax, antecedida por análise exploratória dos dados, com vista a verificar a normalidade das distribuições e os pressupostos da análise fatorial. O KMO foi de 0,86 e o teste de esfericidade de Bartlett foi significativo. Não foram encontrados mais do que $2,15 \%$ de casos omissos por variável. Para verificar a fidedignidade dos fatores gerados foi utilizado o coeficiente alfa de consistência interna.

\section{Resultados}

Inicialmente, seis fatores foram extraídos com base no critério de Kaiser (Gable \& Wolf, 1993), em que o eigenvalue do fator deve ser igual ou maior que 1. De acordo com Tabachnik e Fidell (1996), se o número de variáveis for menor que 40 e o tamanho da amostra for grande, como é o caso deste estudo, o número de fatores indicados por este critério é provavelmente correto. Entretanto, um dos fatores foi descartado por incluir apenas um item. Este item também foi desconsiderado porque não estava alocado em nenhum dos outros fatores. Além disso, integraram os fatores apenas os itens com carga fatorial igual ou maior que 0,30 (veja Tabelas 1 a 5). Neste sentido, dois itens foram descartados, pois não foram alocados em nenhum fator. A solução de 5fatores explicou $31 \%$ da variância.

$\mathrm{O}$ fator 1, denominado Suporte da Professora à Expressão de Idéias do Aluno, inclui cinco itens relativos ao apoio que a professora fornece ao aluno para manifestar sua opinião, gerando um clima de respeito às idéias apresentadas pelos alunos, contribuindo para que o aluno se sinta seguro em manifestar suas idéias em sala de aula.

O fator 2, Autopercepção do Aluno com Relação à Criatividade, inclui quatro itens que dizem respeito à imagem que o aluno tem de si mesmo em relação ao seu nível de criatividade.

O fator 3, denominado Interesse do Aluno pela Aprendizagem, engloba seis itens relativos ao envolvimento do aluno com o trabalho escolar.

Tabela 1. Cargas fatoriais, comunalidades e correlações item-total dos itens que integram o fator 1 (suporte da professora à expressão de idéias do aluno)

\begin{tabular}{llccc}
\hline Item & \multicolumn{1}{c}{ Conteúdo } & Carga & $\mathbf{h}^{2}$ & $\begin{array}{c}\text { Correlação } \\
\text { item-total }\end{array}$ \\
\hline 1 & $\begin{array}{l}\text { A professora dá atenção às } \\
\text { minhas idéias }\end{array}$ & 0,73 & 0,57 & 0,58 \\
12 & $\begin{array}{l}\text { A professora se importa com o } \\
\text { que eu tenho a dizer. }\end{array}$ & 0,66 & 0,52 & 0,58 \\
3 & $\begin{array}{l}\text { Minhas idéias são bem-vindas. } \\
7\end{array}$ & 0,50 & 0,38 & 0,50 \\
& $\begin{array}{l}\text { A professora me dá tempo } \\
\text { suficiente para pensar sobre } \\
\text { uma história que eu tenho que }\end{array}$ & 0,47 & 0,29 & 0,43 \\
& $\begin{array}{l}\text { escrever. } \\
\text { Eu tenho chance de participar de } \\
\text { várias atividades }\end{array}$ & 0,34 & 0,23 & 0,39 \\
\hline
\end{tabular}

Nota . Variância explicada $=7,84$. Índice de fidedignidade $=0,73$. 
Tabela 2. Cargas fatoriais, comunalidades e correlações item-total dos itens que integram o fator 2 (autopercepção do aluno com relação à criatividade)

\begin{tabular}{llccc}
\hline Item & \multicolumn{1}{c}{ Conteúdo } & Carga & $\mathbf{h}^{2}$ & $\begin{array}{c}\text { Correlação } \\
\text { item-total }\end{array}$ \\
\hline 10 & Eu tenho muitas idéias. & 0,59 & 0,42 & 0,44 \\
6 & Eu me acho criativo(a). & 0,58 & 0,40 & 0,51 \\
8 & Eu uso minha imaginação. & 0,49 & 0,30 & 0,43 \\
21 & Eu sinto orgulho de mim. & 0,37 & 0,33 & 0,37 \\
\hline
\end{tabular}

Nota. Variância explicada $=6,60$. Índice de fidedignidade $=0,66$.

O fator 4, Autonomia do Aluno, inclui quatro itens que dizem respeito a um traço de personalidade do aluno associado à criatividade.

Tabela 3. Cargas Fatoriais, comunalidades e correlações item-total dos itens que integram o fator 3 (interesse do aluno pela aprendizagem)

\begin{tabular}{|c|c|c|c|c|}
\hline Item & Conteúdo & Carga & $\mathbf{h}^{2}$ & $\begin{array}{l}\text { Correlação } \\
\text { item-total }\end{array}$ \\
\hline 13 & Eu gosto da matéria ensinada. & 0,72 & 0,54 & 0,50 \\
\hline 15 & $\begin{array}{l}\text { Eu aprendo coisas que realmente } \\
\text { gosto. }\end{array}$ & 0,51 & 0,31 & 0,44 \\
\hline 9 & $\begin{array}{l}\text { Os trabalhos que faço são } \\
\text { divertidos }\end{array}$ & 0,38 & 0,35 & 0,43 \\
\hline 11 & $\begin{array}{l}\text { Quando eu começo uma tarefa, } \\
\text { eu gosto de terminá-la. }\end{array}$ & 0,36 & 0,21 & 0,35 \\
\hline 18 & Eu aprendo muitas coisas. & 0,32 & 0,26 & 0,31 \\
\hline 23 & $\begin{array}{l}\text { Eu pesquiso em livros quando } \\
\text { eu quero saber mais sobre um } \\
\text { assunto. }\end{array}$ & 0,30 & 0,25 & 0,33 \\
\hline
\end{tabular}

Nota. Variância explicada $=6,59$. Índice de fidedignidade $=0,66$.

O fator 5, Estímulo da Professora à Produção de Idéias do Aluno, inclui três itens relativos à postura de incentivo e aceitação por parte do professor às idéias geradas pelos alunos.

Tabela 4. Cargas fatoriais, comunalidades e correlações item-total dos itens que integram o fator 4 (autonomia do aluno)

\begin{tabular}{lllll}
\hline Item & \multicolumn{1}{c}{ Conteúdo } & Carga & $\mathbf{h}^{2}$ & $\begin{array}{c}\text { Correlação } \\
\text { item-total }\end{array}$ \\
\hline 16 & $\begin{array}{l}\text { Eu posso escolher o que eu quero } \\
\text { fazer. }\end{array}$ & 0,59 & 0,40 & 0,40 \\
17 & $\begin{array}{l}\text { Eu fico tão envolvido(a) com as } \\
\text { tarefas que eu não sei o que está } \\
\text { acontecendo perto de mim. }\end{array}$ & 0,43 & 0,23 & 0,34 \\
4 & $\begin{array}{l}\text { Eu procuro fazer as tarefas de } \\
\text { maneiras diferentes. }\end{array}$ & 0,40 & 0,25 & 0,30 \\
5 & $\begin{array}{l}\text { A professora me pede para } \\
\text { mostrar meu trabalho para os } \\
\text { outros alunos. }\end{array}$ & 0,39 & 0,25 & 0,30 \\
\hline
\end{tabular}

Nota. Variância explicada $=5,18$. Índice de fidedignidade $=0,55$.

Para verificar a fidedignidade dos fatores foi utilizado o coeficiente alfa de consistência interna. Os coeficientes alfa de fidedignidade foram: 0,73 para o fator 1, 0,66 para os fatores 2 e 3, 0,55 para o fator 4 e 0,58 para o fator 5 . A correlação item total variou de 0,30 a 0,58 .
Tabela 5. Cargas fatoriais, comunalidades e correlações item-total dos itens que integram o fator 5 (estímulo da professora à produção de idéias do aluno)

\begin{tabular}{|c|c|c|c|c|}
\hline Item & Conteúdo & Carga & $\mathbf{h}^{2}$ & $\begin{array}{c}\text { Correlação } \\
\text { item-total } \\
\end{array}$ \\
\hline 14 & $\begin{array}{l}\text { A professora me pede para } \\
\text { pensar em novas idéias. }\end{array}$ & 0,61 & 0,44 & 0,42 \\
\hline 22 & $\begin{array}{l}\text { A professora me pede para } \\
\text { pensar em muitas idéias. }\end{array}$ & 0,61 & 0,47 & 0,45 \\
\hline 19 & $\begin{array}{l}\text { A professora me pede para tentar } \\
\text { quando eu não sei a resposta para } \\
\text { uma questão. }\end{array}$ & 0,36 & 0,25 & 0,31 \\
\hline
\end{tabular}

\section{Discussão}

Os cinco fatores medidos pelo instrumento construído neste estudo avaliam comportamentos do professor favoráveis à expressão criativa discente, bem como, características do aluno associadas à criatividade. É interessante observar que os fatores da Escala sobre o Clima para Criatividade em Sala de Aula incluem aspectos individuais e ambientais, corroborando a visão sistêmica de criatividade que apresenta este fenômeno como resultado da interação entre indivíduo e o contexto sociocultural (Amabile, 1996; Csikszentmihalyi, 1996, 1999).

Diversos autores têm destacado que além de se promover condições favoráveis ao desenvolvimento de características intraindividuais, tais como, habilidades cognitivas e traços de personalidade associadas à criatividade, importância deve ser dada, também, à identificação de características de um clima de sala de aula propício à emergência de produtos criativos (Fasko, 2000-2001; Fleith, 2001; Novaes, 1992; 2001; Renzulli, 1992; Sternberg, 2000). Três fatores da escala construída dizem respeito a aspectos individuais - Autopercepção do Aluno com Relação à Criatividade, Interesse do Aluno pela Aprendizagem e Autonomia do Aluno - e duas destacam o papel do professor na estimulação da criatividade discente - Suporte da Professora à Expressão de Idéias do Aluno e Estímulo da Professora à Produção de Idéias do Aluno. Neste sentido, os resultados obtidos sugerem que a escala constitui-se em um instrumento útil tanto para fins de pesquisa quanto para diagnóstico de condutas docentes que favorecem o desenvolvimento e expressão das habilidades criativas de jovens alunos. Com relação às implicações práticas do uso deste instrumento, ele pode contribuir na orientação do professor acerca de que aspectos do processo de ensino-aprendizagem devem ser mais estimulados em sala de aula, bem como na indicação de que aspectos da formação do professor merecem ser revistas de forma a levá-lo a implementar práticas encorajadoras da criatividade no contexto escolar. Para isto, recomenda-se a introdução do conteúdo relativo ao que vem sendo pesquisado sobre criatividade nos cursos de formação e capacitação de docentes, paralelamente à maior divulgação de tópicos relativos à educação para a criatividade junto a todos os professores, independentemente do nível de ensino em que atuam (Alencar, 1995; Alencar \& Fleith, 2004a).

É importante destacar que, do ponto de vista metodológico, o índice de fidedignidade obtido para alguns dos fatores da escala, neste estudo exploratório, situa-se abaixo 
do nível ideal. Segundo Gable e Wolf (1993), um critério de retenção dos fatores, considerando-se sua fidedignidade, é um coeficiente alfa de consistência interna igual ou maior do que 0,70 . Neste sentido, sugere-se que esta escala possa ser aperfeiçoada e reaplicada em uma nova amostra de alunos de $3^{\mathrm{a}}$ e $4^{\mathrm{a}}$ séries do ensino fundamental, com vistas a aumentar $\mathrm{o}$ índice de fidedignidade dos fatores.

Avaliar a extensão em que o clima de sala de aula vem favorecendo o desenvolvimento da expressão criativa em sala de aula constitui-se em um grande desafio, especialmente, quando envolve a percepção de alunos tão jovens, como no caso do presente estudo. De acordo com Runco (1993), crianças no início do processo de escolarização têm dificuldade em reconhecer idéias criativas, embora elas sejam capazes de identificar idéias inusuais. Medir criatividade é uma tarefa complexa e difícil. Entretanto, como afirma Treffinger (1986), os mesmos fatores que constituem barreiras ao desenvolvimento das medidas de criatividade são também fontes de entusiasmo e imaginação para o pesquisador.

\section{Referências}

Alencar, E. M. L. S. (1990). Como desenvolver o potencial criador. Petrópolis: Vozes.

Alencar, E. M. L. S. (1995). Developing creativity at the university level. European Journal for High Ability, 6(1), 82-90.

Alencar, E. M. L. S. (1997). O estímulo à criatividade no contexto universitário. Psicologia Escolar e Educacional, 1(1), 29-37.

Alencar, E. M. L. S., Collares, K., Dias, L. \& Julião, S. (1993). Efeitos a curto e médio prazos de um programa de treinamento de criatividade em estudantes do ensino de segundo grau [Resumo]. Em Sociedade Brasileira de Psicologia (Org.), Resumos de comunicações científicas, XXIII Reunião Anual da Sociedade Brasileira de Psicologia, (s.p.). Ribeirão Preto: SBP.

Alencar, E. M. L. S. \& Fleith, D. S. (2003). Criatividade: Múltiplas perspectivas. Brasília: EdUnB.

Alencar, E. M. L. S. \& Fleith, D. S. (2004a). Creativity in university courses: Perceptions of professors and students. Gifted and Talented International, 19(1), 24-28.

Alencar, E. M. L. S. \& Fleith, D. S. (2004b). Inventário de práticas docentes que favorecem a criatividade no ensino superior. Psicologia: Reflexão e Crítica, 17(1),105-110.

Alencar, E. M. L. S., Fleith, D. S. \& Martinez, A. M. (2003). Obstacles to personal creativity between Brazilian and Mexican students: A comparative study. The Journal of Creative Behavior, 37(3), 179-192.

Alencar, E. M. L. S., Fleith, D. S. \& Virgolim, A. M. R. (1995). Fatores inibidores à criatividade em estudantes universitários e professores. Em Associação Brasileira de Psicologia Escolar. Anais do XVII Congresso Internacional de Psicologia Escolar, tomo II, (pp. 105-109). Campinas: Átomo.

Amabile, T. A. (1989). Growing up creative. Buffalo, NY: The Creative Education Foundation Press.

Amabile, T. A. (1996). Creativity in context. Boulder, CO: Westview Press.

Amabile, T. A. (2001). Beyond talent: John Irving and the passionate craft of creativity. American Psychologist, 56(4), 333-336.
Amabile, T. A. \& Gryskiewicz, N. D. (1989). The creative environment scales: Work Environment Inventory. Creativity Research Journal, 2(4), 231-253.

Bruno-Faria, M. F. \& Alencar, E. M. L. S. (1998). Indicadores de clima para a criatividade: Um instrumento de medida da percepção de estímulos e barreiras à criatividade no ambiente de trabalho. Revista de Administração, 33(4), 86-91.

Cropley, A. J. (1997). Fostering creativity in the classroom: General principles. Em M. A. Runco (Org.), The creativity research handbook. Vol. 1 (pp. 83-114). Cresskill, NJ: Hampton Press.

Csikszentmihalyi, M. (1988). Society, culture, and person: A systems view of creativity. Em R. J. Sternberg (Org.), The nature of creativity (pp. 325-339). New York: Cambridge University Press.

Csikszentmihalyi, M. (1996). Creativity. New York: HarperCollins.

Csikszentmihalyi, M. (1999). Implications of a systems perspective for the study of creativity. Em R. J. Sternberg (Org.), Handbook of creativity (pp. 313-335). New York: Cambridge University Press.

Daniels, S. (1997). Creativity in the classroom: Characteristics, climate, and curriculum. Em N. Colangelo \& G. A. Davis (Orgs.), Handbook of gifted education ( $2^{\text {nd }}$ ed., pp. 292-307). Needham Heights, MA: Allyn and Bacon.

Fasko, D. (2000-2001). Education and creativity. Creativity Research Journal, 13(3-4), 317-327.

Feldman, D. H., Csikszentmihalyi, M. \& Gardner, H. (1994). A framework for the study of creativity. Em D. H. Feldman, M. Csikszentmihalyi \& H. Gardner (Orgs.), Changing the world. A framework for the study of creativity (pp. 1-45). Westport, CT: Praeger.

Fleith, D. S. (2000). Teacher and student perceptions of creativity in the classroom environment. Roeper Review, 22(3), 148-153.

Fleith, D. S. (2001). Criatividade: Novos conceitos e idéias, aplicabilidade à educação. Cadernos de Educação Especial, 17(1), 55-61.

Fleith, D. S. (2002). Ambientes educacionais que promovem a criatividade e excelência. Sobredotação, 3(1), 27-39.

Fletcher, W. (1997, 6 de outubro). Creativity is back in fashion. Financial Times, p. 12.

Gable, R. K. \& Wolf, M. B. (1993). Instrument development in the affective domain ( $2^{\text {nd }}$ ed.). Norwell, MA: Kluwer Academic.

Gardner, H. \& Wolf, C. (1994). The fruits of asynchrony: A psychological examination of creativity. Em D. H. Feldman, M. Csikszentmihalyi \& H. Gardner (Orgs.), Changing the world. A framework for the study of creativity (pp. 47-68). Westport, CT: Praeger.

Isaksen, S. G., Lauer, K. J., Ekvall, G. \& Britz, A. (2001). Perceptions of the best and worst climates for creativity: Preliminary validation evidence for the situational outlook questionnaire. Creativity Research Journal, 13(2), 171-184.

Novaes, M. H. (1992). Psicologia da educação e prática profissional. Petrópolis: Vozes.

Novaes, M. H. (2001). Modelos interpretativos da criatividade e alternativas de atuação psicossocioeducativa. Em Z. A. Prette (Org.), Psicologia Escolar e Educacional (pp. 75-86). Campinas: Alinea.

Piirto, J. (1992). Understanding those who create. Dayton, OH: Ohio Psychology Press. 
Renzulli, J. S. (1992). A general theory for the development of creative productivity through the pursuit of ideal acts of learning. Gifted Child Quarterly, 36(4), 17-182.

Runco, M. A. (1993). Cognitive and psychometric issues in creativity research. Em S. G. Isaksen, M. C. Murdock, R. L. Firestien \& D. J. Treffinger (Orgs.), Understanding and recognizing creativity: The emergence of a discipline (pp. 331368). Norwood, NJ: Ablex.

Soh, K. C. (2000). Indexing creativity fostering teacher behavior: A preliminary validation study. The Journal of Creative Behavior, 34(2), 118-134.

SPSS (1998). SPSS graduate pack 8.0 for windows. Chicago: Author.

Starko, A. J. (1995). Creativity in the classroom. White Plains, NY: Longman.

Sterling, A. (2003). Human creativity and chaotic dynamics. Em D. Ambrose, L. Cohen \& A. J. Tannenbaum (Orgs.), Creative intelligence (pp. 147-177). Cresskill, NJ: Hampton Press.

Sternberg, R. J. (2000). Identifying and developing creative giftedness. Roeper Review, 23(2), 60-64.

Sternberg, R. J. (2003). The development of creativity as a decision-making process. Em R. K. Sawyer, V. John-Steiner, S. Moran, R. J. Sternberg, D. H. Feldman, J. Nakamura \& M. Csikszentmihalyi (Orgs.), Creativity and development (pp. 91138). New York: Oxford University Press.

Sternberg, R. J. \& Lubart, T. I. (1999). The concept of creativity: Prospects and paradigms. Em R. J. Sternberg (Org.), Handbook of creativity (pp. 3-15). New York: Cambridge University Press.
Sternberg, R. J. \& Williams, W. M. (1996). How to develop student creativity. Alexandria, VA: Association for Supervision and Curriculum Development.

Tabachnik, B. G. \& Fidell, L. S. (1996). Using multivariate statistics ( $3^{\mathrm{a}}$ ed.). New York: HarperCollins.

Tardiff, T. Z. \& Sternberg, R. J. (1988). What do we know about creativity? Em R. J. Sternberg (Org.), The nature of creativity (pp. 429-440). New York: Cambridge University Press.

Torrance, E. P. (1983). Creativity in the classroom. Washington, DC: National Education Association.

Treffinger, D. J. (1986). Research on creativity. Gifted Child Quarterly, 30(1), 15-19.

Treffinger, D. J. (2003). Assessment and measurement in creativity and creative problem solving. Em J. Houtz (Org.), The educational psychology of creativity (pp. 59-93). Cresskill, NJ: Hampton Press.

Virgolim, A. M. R. (1994). Criatividade e saúde mental: Um desafio à escola. Em E. M. L. S. Alencar e A. M. R. Virgolim (Orgs.), Criatividade: Expressão e desenvolvimento (pp. 43-69). Petrópolis: Vozes.

\author{
Recebido em 04.05.2004 \\ Primeira decisão editorial em 10.02.2005 \\ Versão final em 09.03.2005 \\ Aceito em 21.03.2005
}

